theories ran counter to established biological opinion. However, by recognizing Lysenko's prominence in plant physiology, Roll-Hansen shows why his genetic theories were not so easily dismissed.

The book is strongest in its analysis of the events and trends leading up to the Second World War; the post-war period and the final enshrinement of lysenkoism in 1948 are treated more sketchily. Roll-Hansen gives a prominent place to Marxist philosophy of science in framing debates about agricultural policy and practice. He shows convincingly that Marxist philosophy was not mere windowdressing for many biologists in the Soviet Union at the time, but represented a distinct world-view that many scientists tried to put into practice in their work. In this sense, RollHansen follows and extends the earlier work of Loren Graham, who was one of the first Western historians to seriously explore the role of dialectical materialism in Soviet science. Ironically, it was Lysenko's failure to apply the dialectical method rigorously to his own work that ultimately led to his failure to revolutionize Soviet agriculture.

Throughout the discussion, Roll-Hansen emphasizes both the need to increase production on the farms and the importance, in Marxist terms, of the unity of theory and practice. Soviet agronomists often complained that academic scientists were "obsessed with fruitflies" and had little interest in the crops needed for the rapid improvement of agriculture, and even less interest in peasant farming practices. Unlike many researchers of the time, Lysenko portrayed himself as a practitioner, a man of the people who sought to use the experience of the masses to improve both his theories and his practical breeding programmes.

Roll-Hansen also emphasizes the controversies that existed within Soviet biology and agriculture about mendelian theory. As he points out, none of these issues was peculiar to Soviet biology. Many of Lysenko's ideas about phenotypic plasticity, the physiological aspects of development, and the over-simplicity of the atomistic mendelian gene were remarkably similar to those of Richard Goldschmidt in Germany, Ross Harrison in the United States and Albert Dalcq in Belgium. Similarly, neo-lamarckism retained a strong following in this period in France and Germany. Even in the United States, where mendelian theory had been accepted early on, its application to agriculture had barely begun to yield results.

Particularly problematic for Soviet geneticists was the association of mendelian theory in the West with opposition to the darwinian theory of natural selection and with eugenics. Darwinism, with its emphasis on variation and selection, had received strong support in Russia since the nineteenth century. Mendelian genetics, which emphasized the stability of the gene, and Wilhelm Johannsen's pure-line experiments, which showed the limits of selection, were seen as contradictions to Darwin that undermined its application to agriculture. The fact that many supporters of classical genetics had also supported eugenics did not place mendelian theory in a particularly favourable light: it was held up as an example of reductionistic, atomistic, bourgeois science.

In his concluding chapters, Roll-Hansen describes the debate about Lysenko's programmes throughout the 1930s and 1940s. Questions were raised about how valid his practical results really were (he was accused of over-optimistic reporting, if not the outright falsification of field results), about the demonstrability of lamarckian inheritance, and about his frequent refusal to deal with criticism. In the years immediately after the war, various groups in the scientific community severely criticized Lysenko's work and sought to have his policies marginalized. It was only the heightened tensions of the Cold War and Stalin's personal intervention that turned the tide. Lysenko's theories and policies were finally given official sanction at a 1948 meeting of the Lenin Academy of Agricultural Science. By this time many of his opponents had been silenced through arrests or imprisonment.

The one deficit in this otherwise fine book is the lack of integration between the scientific and political backgrounds. Earlier treatments of the Lysenko episode emphasized the political to the virtual exclusion of the scientific, but Roll-Hansen goes in the opposite direction. His choice of focus adds important new information and analysis, but it is not clear, for example, in the few pages devoted to events leading up to the 1948 congress, what role Stalin and the Central Committee of the Communist Party actually played, or how the tide turned so rapidly in favour of Lysenko.

Roll-Hansen has made a major contribution to our understanding of the Lysenko case. His book is a significant addition to the literature on Russian biology, genetics and agriculture. Garland E. Allen is in the Department of Biology, Washington University, St. Louis,

Missouri 63130, USA.

\title{
The bigger picture
}

\section{Art and Science \\ by Siân Ede \\ I. B. Tauris: 2005.208 pp. $€ 14.95, \$ 24.50$}

\section{Ingeborg Reichle}

Is science the new art? With this provocative question, Siân Ede, arts director of the UK branch of the Calouste Gulbenkian Foundation, draws us into her latest work, Art and Science. In this intelligent and stimulating book,
Ede examines the diverse responses of contemporary artists when they are faced with recent scientific and technological advances. She likewise looks at contemporary science, where the search for truth and beauty, and the production of compelling images, seem to suggest an almost artistic endeavour.

Ede contrasts selected works of contemporary art with recent scientific developments to demonstrate that art today not only serves

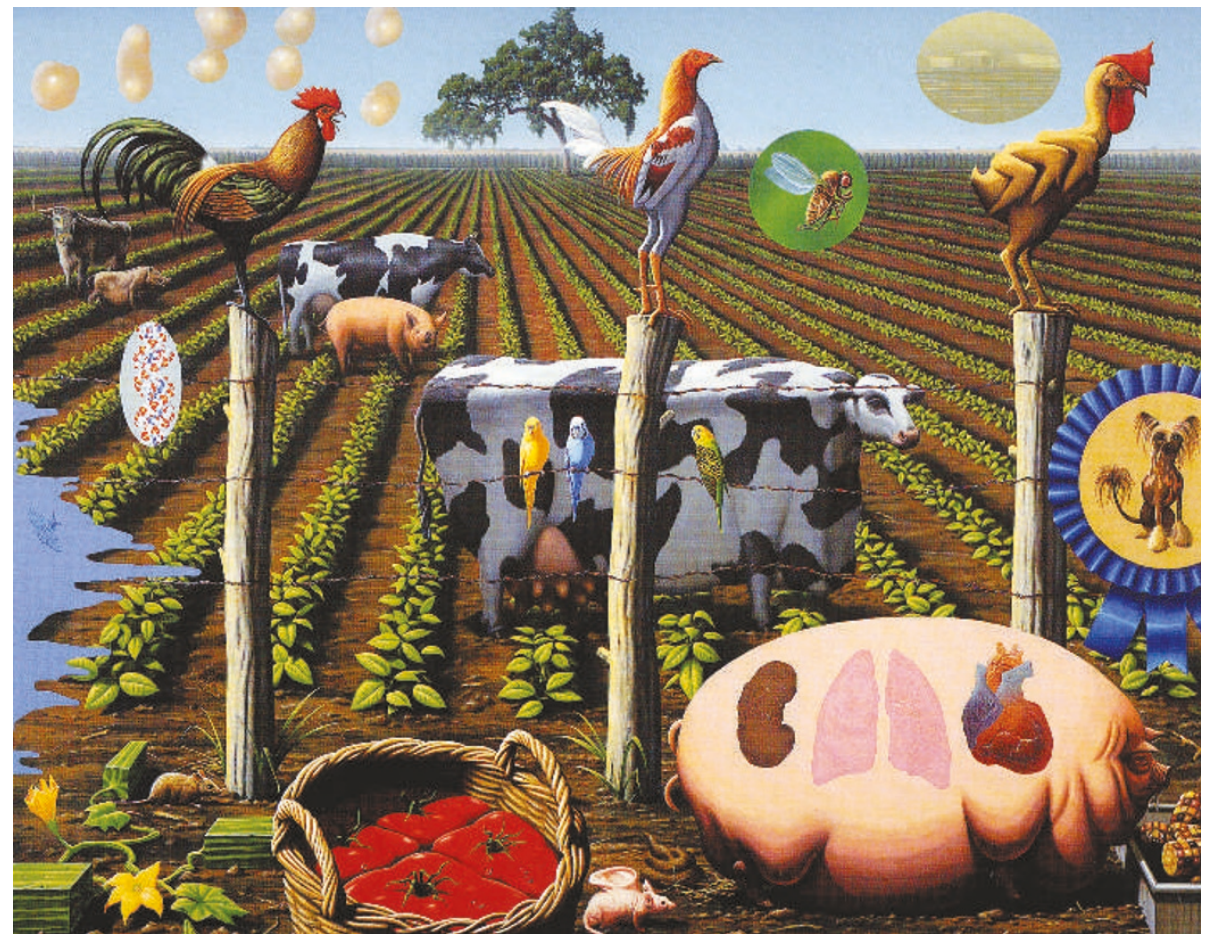

Alexis Rockman's painting The Farm questions the future of genetic engineering. 
to comment on science, but also represents a form of research and knowledge production in its own right, though one belonging to a radically different epistemological tradition. Science, engineering and technology shape the world in which we live, but Ede shows us the role played by art in the ever more complex interplay of forces between science, technology and society. It is the artist who asks about the social effects of scientific developments and challenges the changing scientific concepts of life itself - these questions become ever more urgent with every scientific advance. Moving beyond the postulated dichotomy of the objective sciences and the subjective arts, the impressive abundance of contemporary artworks cited by Ede shows us that art is no longer limited to the production of beautiful atefacts, but has established its role as a legitimate form of knowledge production in its own right.

The engagement of art with science ranges from artists' iconological handling of scientific imaging to research projects executed as artistic endeavours by artists working in the laboratory. An example of the former is the work of Neal White, one-time artist in residence at the human genome project at Hinxton near Cambridge, UK; an example of the latter is the work of the Portuguese artist Marta de Menezes, who uses the laboratory technique of microcautery to modify the patterning of butterfly wings. Such artistic interventions in genetics and biological forms have made possible new means of artistic expression and art forms.

Some of the insights that art provides into the latest hot topics in science, such as cloning or the production of artificial chimaeras, have been extensively addressed by Suzanne Anker and Dorothy Nelkin in their book The Molecular Gaze (Cold Spring Harbor Laboratory Press, 2004). The use of biological materials by artists ranges from tissue engineering to stem-cell technologies and even transgenic animals, a phenomenon that raises ethical questions with regard to both scientific and artistic endeavours.

New directions in research, such as those offered by neurobiology and studies of consciousness, provide greater insight into the working of the mind, and molecular biology continues to provide us with a better understanding of the structure of the living world. Their scientific explanations of the structures and processes of body and mind challenge our conception and understanding of what we call 'human nature'. But individuality and self must be more than mere bundles of impulses, sensations and chemical processes.

Through the use of video endoscopies in her 1994 work Corps étranger, artist Mona Hatoum blurs the boundaries between the inner and the outer, allowing the viewer to participate in her own stream-of-consciousness and somatic experiences. Collaborating with neuroscientists, artist Annie Cattrell uses functional magnetic resonance imaging (fMRI) data to create three-dimensional, amber-coloured works in resin that are then embedded in solid, clear, resin cubes or 'brain boxes' (see Nature 424, 18, 2002). Whether working with brain scans produced by advanced imaging processes or simply with traditional media, the focus of the artistic process is increasingly the diversity of human experience, something that often does not lend itself to portrayal using standard scientific procedures.

From the end of the nineteenth century onward, art has increasingly turned away from the classical quest for order, and has struggled on many levels with the disintegration of a uniform world view and a coherent conception of humanity. Scientific images today offer us amazing insights, but they must still be viewed as historical snapshots. Although modern science can provide us with ever more detailed pictures of the inner workings of our bodies and of the living world, the influence of such images on our understanding of the nature of humanity remains an issue for social discourse.

Ede not only offers an overview of contemporary art practices, but also examines their philosophical background. Additionally, the artworks discussed are accompanied by extensive examples of contemporary science and research, providing further insight into the newest scientific developments. The book is an excellent contribution to the literature in the field of art and science, and provides a perspective that reaches far beyond the usual approaches to the relationship between, and intersection of, art and science.

Ingeborg Reichle is an art historian and theorist at the Berlin-Brandenburg Academy of Sciences and Humanities, Jägerstrasse 22/23,

Berlin 10117, Germany.

\section{Focusing on the stars}

\section{Stargazer: The Life and Times of the \\ Telescope \\ Fred Watson \\ Da Capo Press: 2005.342 pp. $\$ 24.95$}

\section{Robert H. van Gent}

The telescope symbolizes the science of astronomy and had

a pivotal role in the development of early modern science. Several excellent historical studies have already been written about it, notably André Danjon and André Couder's Lunettes et Télescopes in 1935, Henry King's The History of the Telescope in 1955, and Rolf Riekher's Fernrohre und ihre Meister in 1990.

As we approach the fourth centennial of the invention of the telescope, the Australian astronomer Fred Watson presents a well-written, up-to-date history of the invention and development of the telescope and its impact on astronomy. As the astronomerin-charge at the Anglo-Australian Observatory at Coonabarabran in New South Wales, Watson is well equipped to write such a history. He tells the fascinating story of the invention of simple telescopes by Dutch spectacle-makers in the early years of the seventeenth century, and recounts their evolution into the modern telescopes of today.

The reliably documented history of the telescope begins in
September 1608, when the Middelburg spectacle-maker Hans Lippershey submitted a request for a patent on his invention. But Watson also dwells on the (unlikely) possibility that primitive telescopes had been known to the ancient Mesopotamians, and to Hellenistic and medieval scholars in Europe.

A stronger case can be made for the so-called Elizabethan telescope, an early reflecting telescope described in the works of the Englishmen Thomas Digges and William Bourne, but the evidence suggests that it existed only in the minds of those who wrote on it, rather than in reality. Although the inventors of the refracting telescope were Dutchmen, it fell to Galileo, Thomas Harriot and Simon Marius to use it to observe the Universe. Their observations soon provided proof for the Sun-centred copernican model of the heavens. Christiaan Huygens, Johannes Hevelius and William Herschel all made key discoveries using telescopes that they had designed and built themselves.

After the early successes, Watson goes on to describe the subsequent improvements of the refracting and reflecting telescopes, with considerable attention to detail. In

Star performer: Galileo's telescope from the early seventeenth century. 